\title{
EL DEVENIR DEL TEATRO DE UNAMUNO EN LATINOAMÉRICA
}

\author{
María del Puerto GÓMEZ CORREDERA \\ Laboratoire en Langues et Littératures Romanes, \\ Études Basques, Espace Caraïbe \\ Université de Pau et Pays de l'Adour \\ puerto.gomez@wanadoo.fr
}

Resumen: Se trata de estudiar las circunstancias en la cuales las obras teatrales de Unamuno han sido representadas en Latinoamérica y cómo sus posteriores adaptaciones se han difundido allí desde principios del siglo XX hasta hoy.

Abstract: The object is to study the circumstances in which Unamuno's plays have been played in Latin America, and the spread of their posterior adaptations from the beginning of the $\mathrm{XX}^{\text {th }}$ century until our days.

Palabras clave: Unamuno. América Latina. Teatro. Puesta en escena.

Key words: Latin America. Theatre. Performance. 
El teatro de Unamuno es considerado esquemático, filosófico y poco teatral, lo que le ha valido el ser poco representado. Aun así, como demostré en mi tesis ${ }^{1}$, es un teatro que forma parte del panorama teatral europeo por encontrarse vinculado a las tentativas renovadoras llevadas a cabo en la primera mitad del siglo Xx. Unamuno eligió un teatro experimental donde la palabra era la gran protagonista, por lo que el texto debía permanecer libre de acotaciones — los diálogos y monólogos, según él, se bastaban a sí mismos para marcar el tono o las actitudes- y la dimensión escénica era reducida a la más estricta desnudez. Con ello, sólo buscaba poner de relieve las verdaderas pasiones, sin disfraces, para aportar más intensidad y emoción al teatro. Estaba convencido de que era lo que el público buscaba y que sería la solución a un teatro comercial anquilosado por las excesivas decoraciones que intentaban paliar la falta de calidad artística de las piezas.

En el presente estudio, intentaremos demostrar que la vigencia del teatro unamuniano no se limita a España o Europa, sino que se puede observar su presencia en Latinoamérica también. Semejante investigación resulta bastante difícil dado el gran número de países concernidos, la distancia geográfica y temporal, la falta de archivos, la pérdida de éstos con las dictaduras o la falta de estructuras dedicadas a su conservación. A esta situación ha contribuido el hecho de que durante mucho tiempo los elementos espectaculares de las representaciones fueron considerados efímeros e innecesarios para el estudio teatral. Afortunadamente, los críticos se interesan cada vez más por la dimensión escénica del teatro y ponen de relieve que las puestas en escena, en algunos casos, son verdaderas creaciones artísticas que responden a criterios muy estrictos y que ponen de realce - e incluso compensan - las posibles deficiencias del texto teatral.

El estudio destacará la evolución del teatro unamuniano en Latinoamérica desde sus inicios hasta la actualidad, para intentar ver cuál ha sido su alcance, su evolución y lo que ha aportado a este arte. Sin embargo, no en todos los países se han registrado estrenos de las obras de Unamuno. Por ejemplo en el Teatro Nacional Chileno que cofundó José Ricardo Morales ${ }^{2}$ no figura ninguna obra unamuniana y en Perú, tan sólo hemos encontrado

${ }^{1}$ Fortune et Infortunes du théâtre d'Unamuno: péripéties et avatars de Fedra et El Otro, presentada en la Universidad de Pau et des Pays de l'Adour (mayo de 2005).

2 Escritor y hombre de teatro que participó en el grupo El Búho y se exilió en Chile en 1939 como consecuencia de la guerra civil. Allí se encargaba de difundir el teatro clásico y contemporáneo español, contribuyendo a la renovación de la escena chilena. 
el paso de compañías teatrales españolas o argentinas como indica Vargas Llosa en su libro Como pez en el agua .

Por otro lado, entre los países que cuentan en su haber un mayor número de representaciones de este teatro se encuentra Argentina, en concreto Buenos Aires, seguido de México. Este hecho se explica por la presencia de exiliados españoles que eligieron primordialmente estos países como residencia durante la guerra civil española y su posterior dictadura:

Así, por ejemplo, en el Teatro Avenida de Buenos Aires se estrenaron durante la década de los años cuarenta obras de mucha mayor calidad literaria y escénica que las representadas en el Teatro Español de Madrid, obras que significaban la continuidad de nuestra mejor tradición teatral republicana, heredera de Valle-Inclán y de García Lorca, ambos fallecidos en 1936 (Aznar, 1999: 12).

Una diferencia con las representaciones de Unamuno en España es que no todas las obras fueron representadas en Latinoamérica. De La princesa doña Lambra, La difunta, La venda, La esfinge, Sombras de sueño, El pasado que vuelve o Medea no hemos encontrado rastro, lo cual no quiere decir que no haya habido representaciones, pero son puestas en escena de las que queda poca o ninguna información o que fueron montadas por compañías de aficionados cuyo trabajo es más difícil de conocer. El resto de las obras de Unamuno tuvieron suertes distintas en varios países a lo largo del siglo.

Tres son las obras de las que hemos encontrado una sola representación. La lectura de Soledad ${ }^{4}$ en 1957, por el elenco argentino Las dos carátulas ${ }^{5}$, se encuentra entre las lecturas que ofrece esta compañía semanalmente de los textos más significativos del teatro. Posteriormente, la Comediata produjo en 1990 El hermano Juan o el mundo es un teatro ${ }^{6}$, una de las obras menos representadas de Unamuno. La pieza fue puesta en escena en la sala mexicana la Casa de la Cultura Jesús Reyes Heroles por Carlos de Pedro, quien parti-

3 «Fui varios sábados, al teatro Segura, o al Municipal, o al pequeño escenario de la Escuela Nacional de Arte Escénico [...] a ver compañías españolas o argentinas —en esa época, parece mentira, en Lima ocurrían esas cosas - , que montaban piezas de Alejandro Casona, de Jacinto Grau, o de Unamuno» (Vargas Llosa, 1993:122)

${ }^{4}$ Escrita en 1921 y estrenada en 1953 en el María Guerrero por José Luis Alonso y Carmen Troitiño.

5 Este elenco fue creado el 9 de julio de 1950 y realiza lecturas de obras tanto de autores nacionales, como extranjeros y clásicos, desde Sófocles, hasta Griselda Gambaro, pasando por Shakespeare, Lorca o Ibsen.

${ }^{6}$ Fue escrita en 1929 y publicada en 1934 tras la desesperación del autor, que aunque contrario a publicar sus piezas teatrales, no tuvo más remedio al encontrarse una y otra vez los mismos obstáculos empresariales a la hora de intentar estrenarlas. 
cipaba también como actor. Lamentablemente, en el CITRU ${ }^{7}$ no consta ninguna actividad escénica de Carlos de Pedro o de la productora Comediata en los años posteriores a esta escenificación. Pero la más destacada dentro de este apartado de obras de una sola representación es Raquel encadenada (1921), ya que su puesta en escena es una de las primeras representaciones de una obra teatral de Unamuno en Latinoamérica. Se debe destacar el hecho de que fuese la compañía argentina compuesta por Matilde Rivera y Enrique de $\operatorname{Rosas}^{8}$ la encargada de estrenar la pieza. No es extraño que este elenco pusiera en escena obras de Unamuno, ya que a pesar de las trabas empresariales, el director intentaba introducir autores que eran conocidos por sus textos renovadores para dar nueva vida al teatro argentino 9

Del 7 al 13 de septiembre de 1926, la compañía escenificó la pieza en el Tívoli para la inauguración de su temporada antes de volver a Buenos Aires y montarla en el Ateneo el 10 de junio de 1927 (Urquiza, 1973: 220). Esta representación pasó bastante desapercibida y debió su eco sobre todo al renombre de la compañía. El crítico M. Rodríguez Codolá achaca su fracaso al excesivo realismo en el lenguaje de la pieza de Unamuno y no a la puesta en escena, ni a los actores:

Requiérese de una actriz que se penetre bien de la compleja figura de Raquel, para animarla debidamente, para que convenza a través de las situaciones. Lo consiguió así la señora Rivera. [...] Muy acertado siempre el señor de Rosas: muy acertado en la sencillez de que revistió el tipo avaro para quien el dinero es lo único que manda en su corazón (Rodríguez Codolá, 1926:10).

Tres son igualmente las obras más representadas en España que coinciden con las obras de mayor repercusión en Latinoamérica. Fedra con dos puestas en escena y dos lecturas, El Otro con tres puestas en escena y una lectura, y Todo un hombre con seis puestas en escena, una lectura, tres adaptaciones al cine e incluso una telenovela.

$\mathrm{Fedra}^{10}$ ofrece gran interés para los escenógrafos pues es considerada como la primera obra de madurez de Unamuno, ya que en ella establece sus

${ }^{7}$ Centro Nacional de Investigación, Documentación e Información Teatral Rodolfo Usigli.

8 1889-1948. Nombre artístico de Dionisio Russo.

${ }^{9}$ El elenco puso en escena en Argentina obras como El magnífico cornudo de Fernand Crommelynck, Padre de Strindberg o El pato salvaje de Ibsen, asimismo potenciaba los talentos sudamericanos escenificando obras como Veinticuatro horas dictador de Enrique García Velloso.

${ }^{10}$ Escrita en 1910 y estrenada el 28 de marzo de 1918 en el Ateneo de Madrid, por Cipriano Rivas Cherif en una representación privada, por no haber haber encontrado un teatro por la negativa de los empresarios a estrenar una obra de Unamuno por considerarlo como teatro poco comercial. 
criterios de desnudez escénica para la renovación teatral: la escena concebida por el escritor se reduce a una sábana blanca como fondo, una mesita y tres sillas.

Las dos lecturas radiofónicas no revisten gran importancia, ya que se emitieron en Argentina en 1964 (el 27 de septiembre por LRA RN, la primera y el 1 de diciembre en Radio Municipal, la segunda) y se enmarcan dentro de los festejos que tuvieron lugar en conmemoración del nacimiento de Miguel de Unamuno. Ninguna de las dos tiene otra intención que la de rendir homenaje al escritor, sin ningún objetivo de renovación, de hecho, según el registro, la segunda sólo dura cinco minutos.

$\mathrm{Al}$ contrario, las dos puestas en escena aparecen vinculadas a proyectos de renovación teatral. La primera tuvo lugar en 1964 en el teatro argentino de la Recova, un conventillo convertido en teatro y que se situaba en Libertador y Callao. La dirección corrió a cargo de Julio Piquer ${ }^{11}$, quien recibió el premio de la crítica por el montaje ese mismo año y estuvo interpretada por Elisa Barbieri en el papel principal. Si bien el teatro ha desaparecido y no se guardan archivos de su actividad, Szuchmacher recuerda la representación como parte de los intentos de renovación llevados a cabo en los 60 con la utilización de nuevos espacios. En efecto, la representación de Fedra se hizo en una escena situada «dentro de un cuarto de 8 metros por 4 [...] con los espectadores sentados en almohadones» (Szuchmacher, 2005: 1). Aunque Rubén Szuchmacher no nos ha podido facilitar más datos que los que incluye en su artículo, se trata de una puesta en escena singular, ya que en un espacio tan concentrado no pudo haber mucho mobiliario, lo que corresponde a los deseos unamunianos de desnudez y esencialidad. Además, los asientos propuestos permitirían al espectador romper con los convencionalismos establecidos en un teatro habitual y sentirse más cerca de la acción, más involucrados, lo que conviene a los preceptos de búsqueda de emoción del escritor.

Más tarde, el 19 de noviembre del 2001, Daniel Ruiz dirige en Argentina un montaje de Fedra, con Esther Goris, Jorge Petraglia y demás elenco. Lo curioso de esta puesta en escena es que se hizo en modalidad semimontada.

11 Estudió en el Instituto de Arte de la Universidad de Buenos Aires. Hasta su muerte en el 2004, estuvo siempre preocupado por ofrecer un teatro de calidad, integró el elenco GeitUBA, al que dirigió en obras como Yerma de García Lorca, en 1971 y Los etcéteras de Don Simón de Pemán, en la temporada 1979/80 entre otras. Más tarde puso en escena también Bodas de sangre de García Lorca en 1980, donde el papel de madre lo asumía un hombre; Aquí nadie paga de Dario Fo en 1982 o La dama boba de Lope de Vega en 1984. 
Es una forma que está a mitad de camino entre el teatro leído y el teatro montado y que cuenta con el apoyo del público:

En el escenario vacío, un grupo de actores, libreto en mano o con la letra prendida con alfileres, va dando vida al texto de un autor [...] No están ensayando, aunque lo parezca -porque no hay escenografía, ni luces, ni tienen la ropa apropiada de los personajes que interpretan - [...] Lo interesante es que el semimontado es un intento de romper esquemas, de mostrar textos y establecer dentro de un tiempo muy limitado, una relación autor-director-actorpúblico que salga de los preceptos institucionalizados (Itzcovich, 1997: 1).

Este formato corresponde mucho a los dictados de Unamuno sobre su teatro, pues al ser semimontada no se requiere mobiliario, ni vestuario. La propia Esther Goris nos ha confesado que se trató de una lectura en la que no se podía resaltar ningún aspecto espectacular, todo estaba en la palabra. Los actores aparecían en una escena desnuda, donde el texto era el principal protagonista ya que:

la función del actor en una lectura es la de encarnar el texto para que llegue al espectador de forma clara y precisa, y dar las suficientes pistas para que el público imagine el resto. Es cierto que la creación de un personaje debe ser también física, pero este aspecto puede ser sugerido con una buena utilización de la palabra y de una gestualidad, mínima pero necesaria, que acompaña a todo actor cuando lee (Ragué, 2006: 39).

El Otro $^{12}$ ha llamado la atención de varios directores latinoamericanos, por sus juegos de dualidad y las posibilidades que ofrece desde un punto de vista escénico al ser considerada la obra de Unamuno más acabada.

De ella, se conoce una lectura que se hizo en la cadena paraguaya RN Asunción en junio de 1957. Pero sin duda, son más importantes las tres puestas en escena por su aporte escénico a la obra. La primera representación fue la del argentino Luis Arata ${ }^{13}$, en el teatro San Martín ${ }^{14}$, del 27 de julio hasta el 17 de agosto de 1934, para la que contó con la ayuda de Lola Membrives que se encargó de la dirección. Ya entonces, los argentinos conocían la

12 Escrita en 1926 y estrenada en 1932 por Cipriano Rivas Cherif.

13 1895-1967. Creó su propia compañía en 1919 con la que realizó numerosas giras artísticas. En 1943 fue elegido presidente de la Casa de Teatro.

${ }^{14}$ Teatro de la calle Esmeralda 255 en el cual cantó Carlos Gardel y que fue demolido, no tiene nada que ver con el actual Teatro San Martín. 
obra teatral de Unamuno con las representaciones de Todo un hombre y $R a$ quel, ofrecidas por la compañía de Enrique De Rosas y Matilde Rivera.

La actuación de Luis Arata en el papel de Otro no convenció a toda la crítica. Mientras algunos elogiaron su labor de actor, definiéndole como «medido y justo, con sobriedad cuando era necesaria, con vigor interior y exterior cuando era oportuno» (La Prensa, 1934), la mayoría consideró su actuación algo repetitiva en ademanes y gestos y un tanto exagerada, hasta el punto de que algunos se permitieron aconsejarle que «si en las futuras representaciones marca más en meditación y menos en locura la inquietud del personaje y vuelve más sobrios su gesto y su ademán, habrá ganado una batalla» ( $\mathrm{La} \mathrm{Na}$ ción, 1934) ${ }^{15}$. Por el contrario, Luisa Vehil en el papel de Damiana obtuvo los elogios de la crítica, sobre todo en su expresividad, al igual que Felisa Mary en el personaje de Ama, ya que logró «en todo momento el efecto requerido, especialmente el último acto, que dijo con certera eficacia» (M.C., 1934).

La escenografía, hecha por Felipe Guibourg, fue aplaudida unánimemente por su expresividad al construir un decorado de corte realista, aunque muy depurado, lo que suponía una escena vanguardista para los gustos de la época:

Los decorados y muebles [...] contribuyeron grandemente a lograr el ambiente de aplastante y sombrío misterio que requiere la obra de Unamuno. La impresión de sordas y frías paredes de piedra que como su destino, como una fatalidad pesa sobre los tres primeros actos se trocó en el epílogo [...] en el alivio del cielo que se asoma por la balconada en que se produjo la tragedia (M.C., 1934).

La única foto a la que hemos tenido acceso muestra la escena utilizada para los tres primeros actos. En ella el ambiente lúgubre se construye con paredes de líneas oblicuas que dan la impresión de un embudo que se cierra sobre los personajes y cuya única salida es la puerta, situada en el fondo de la escena, que conduce al sótano. Como decoración, sólo se aprecia un sillón sobrio que llama la atención por sus formas rectilíneas. Además, el director realza la oposición entre las dos mujeres con la vestimenta, ya que Laura y Damiana llevan trajes de colores opuestos: blanco y negro.

La puesta en escena respetó de esta manera los dictados teatrales unamunianos, conjugando desnudez y funcionalidad, y a pesar de una crítica divi-

15 En este caso, como en otros, no puedo indicar la página, ya que son recortes de periódicos que la Casa Museo Unamuno me ha facilitado y en los cuales sólo figura la fecha de publicación. 
dida en cuanto a la actuación de Arata, el montaje gozó de un gran éxito de público, ya que fue interpretada más de cincuenta veces, resultando la pieza más representada en vida del autor.

Algunos años más tarde, Unamuno aparece ligado de nuevo a una tentativa renovadora del teatro, ya que El Otro fue puesta en escena en Argentina por la compañía libre de Florencio Sánchez, en el 50, en el Teatro del Pueblo $^{16}$. Éste fue uno de los primeros teatros independientes de América Latina, ya que ofrecía los textos teatrales más significativos para intentar proponer alternativas a la escena comercial. Considerado como un teatro de resistencia, porque «gran parte de la población, opositora a las políticas gubernamentales encontraron en las salas de los teatros independientes sus canales de participación y de expresión» (Szuchmacher, 2005: 1), no hubo una política de preservar sus archivos que se han perdido o quemado, por lo que resulta muy difícil conseguir información.

Mejor documentado está el montaje de Javier Vidal en 1986 con el grupo Theja en el Ateneo de Caracas. Esta puesta en escena de El Otro formaba parte del ciclo Cincuenta años después, en el que cosechó grandes éxitos de público y crítica, al obtener el premio al mejor director, al mejor actor principal y el premio municipal a la mejor producción teatral de ese año.

El director propone un montaje muy cuidado, en el que pone todos los elementos escénicos al servicio del texto para destacar la temática de la dualidad. Por ejemplo, la escena es bifrontal con forma de un triángulo isósceles: el lado mayor constituye el fondo de la escena en el que hay un gran espejo y en los otros dos lados del triángulo se sienta el público de manera simétrica. De esta manera, el espectáculo es desdoblado por el espejo, en el que se reflejaba el público también. Esta escena múltiple respeta los deseos de desnudez de Unamuno, ya que tan sólo contiene algunas sillas cubiertas de una tela blanca, evitando así cualquier distracción.

El vestuario se utilizó de forma acertada para reflejar el yo interior de los personajes. Por ejemplo, para marcar la oposición entre Laura y Damiana, la primera aparece vestida de manera tradicional: con un moño, vestido blanco y chal negro; mientras que la segunda se presenta con un aspecto más moderno y de mujer liberada: pelo corto, vestido, sombrero y guantes negros.

De la misma manera, el director se valió de los movimientos y gestos para reforzar los conflictos internos y externos de los protagonistas. Por ejemplo,

\footnotetext{
16 Fundado por Leonidas Barletta en marzo de 1931.
} 
Otro se acerca al espejo a la hora de explicar a Ama la lucha con su hermano, mostrando así la dualidad, para terminar sentándose y volver hacia Ama arrastrándose, para expresar su desesperación ante tal conflicto. Igualmente la lucha entre las dos mujeres se hace más manifiesta con la muerte de Otro, ya que «las dos mujeres corren y se abrazan con desesperado odio y se pegan al espejo violentamente» ${ }^{17}$, haciendo explotar toda la rabia contenida, como si se reprochasen la muerte de Otro y al mismo tiempo se uniesen en el dolor.

La música de un violonchelo acompaña en todo momento las diferentes escenas para especificar su ritmo y poner de relieve los momentos claves de la obra. Por ejemplo, el primer acto pasa de un ritmo andante, es decir, con un tempo moderado, a fuoco, es decir, un ritmo rápido. Este ritmo corresponde a la tensión que aumenta al descubrir Ernesto en la última escena el misterio planteado en la primera: el cadáver del otro.

Javier Vidal huye del naturalismo y construye un montaje de corte vanguardista que se pone también de manifiesto con la iluminación que procede de «unos velones que se apoyaban con una iluminación gótica de corte expresionista», como él mismo nos ha confesado. Se sirve de ella para dar mayor expresividad al texto. Por ejemplo al principio del segundo acto, la escena permanece en la penumbra mientras habla Ama para mostrar que no desea que se esclarezca el misterio de la identidad del cadáver del sótano. La escena se ilumina con la intervención de Ernesto, que no conforme con las explicaciones de Ama, intenta buscar respuestas a tal secreto.

Javier Vidal ha modernizado el texto al suprimir ciertas réplicas que consideraba demasiado cultas o que juzgaba nocivas a la fluidez. Además, ha incluido algunos versos del poema Vendrá la noche de Unamuno, entre el segundo y el tercer acto, en el que se suicida Otro, para realzar la tragedia con el color negro y la oscuridad de la noche, símbolos ambos de muerte y de misterio.

Sin duda alguna, este montaje de El Otro es el más novedoso y el director ha encontrado un sutil equilibrio entre los elementos escénicos que realzan el significado interno del texto. La representación constituye un verdadero intento de renovación y de rescate del teatro unamuniano, mostrando que una buena puesta en escena puede obtener un gran éxito.

A pesar de todo, la pieza de más renombre y de mayor éxito en Latinoamérica ha sido Todo un hombre, adaptación de la obra Nada menos que

17 Libreto facilitado por Javier Vidal con las anotaciones escénicas. 
todo un hombre, de Miguel de Unamuno. No sólo han alcanzado fama las adaptaciones cinematográficas sino también las representaciones. Para éstas, los directores han utilizado siempre la versión hecha por Julio Hoyos y estrenada por Ernesto Vilches el 19 de diciembre de 1925 en el Infanta Beatriz. Esta versión obtuvo gran éxito y la crítica elogió «su respeto absoluto para con caracteres y escenas» (CH., 1931). Del mismo parecer es Antonio Machado, gran admirador de la obra unamuniana, quien reconoce «la honradez del adaptador», pues «apenas hay en la comedia una palabra que no sea de Unamuno» (Machado, 1925: 4).

Si bien es cierto que, aunque en general Julio Hoyos respetó todos los diálogos de la nivola, se vio obligado a hacer cambios para remplazar la parte narrativa. Entre las diferencias, encontramos el hecho de que la figura del padre desaparece y sus propósitos son puestos en boca de la madre, lo que cambia el carácter reprimido que Unamuno le había dado. Además, los dos pretendientes - el uno representaba el carácter cobarde y fanfarrón, el otro el espíritu práctico- son fusionados por Julio Hoyos en uno solo. Se introducen igualmente nuevos personajes, como es el caso de los criados que sirven para anunciar las entradas de otros personajes. También es nuevo el personaje del médico, don Alberto, que sirve como interlocutor de Julia, dándole la oportunidad de expresar sus dudas en voz alta y además da noticias de lo que pasa fuera de escena, como por ejemplo anunciar la muerte de Alejandro y su mujer. De esta manera, Julio Hoyos se mantiene fiel al espíritu unamuniano que no quería una muerte en escena, como dejó bien claro en el exordio de Fedra ${ }^{18}$. Hasta aquí, los cambios no llaman particularmente la atención, pues obedecen a la teatralización de la novela y los personajes añadidos tienen características similares a otros creados por Unamuno en otras de sus obras ${ }^{19}$.

Sin embargo, en la tercera jornada, Julio Hoyos introduce personajes como la marquesa y Margot, dos amigas del conde que servirán para hacer un breve retrato de la sociedad de apariencias de la que Alejandro huye, pero sobre todo para sembrar la duda en cuanto a las relaciones entre Julia y el conde Bordaviella, añadiendo escenas nuevas que aparentemente no fueron del gusto de Unamuno: el escritor salmantino hizo saber en su prólogo al Hermano Juan que la adaptación había «empequeñecido su novela» (Salado, 1935).

\footnotetext{
18 «Una muerte en escena sólo convendría a una actriz de ésas que tienen una colección de muertes para mostrar sus habilidades escénicas» (Unamuno, 1959: 394).

${ }^{19}$ Un médico, por ejemplo, aparecía también en Fedra, donde era el confidente de Pedro y anunciaba la muerte inminente de la protagonista.
} 
No fue del mismo parecer el público, ya que la obra fue todo un éxito al ser representada «en toda España, en Portugal, en Italia, en Alemania, en Austria, etcétera», rindiendo "veinticinco mil duros de utilidad» (Salado, 1935) y fue objeto de críticas muy positivas, en las que se resaltaba la labor de sus dos actores principales, Ernesto Vilches e Irene López Heredia:

Ernesto Vilches, en su corpulencia y aspecto físico, no es el Alejandro de «Nada menos que todo un hombre». Sin duda, el gran actor, dándose cuenta y afrontando, como gran actor, la dificultad, ha buscado compensación y la ha encontrado cumplidamente en la caracterización perfecta, en la pausa del hablar, con un leve dejo criollo: en la compostura de la fisionomía, que una sonrisa hubiera deshecho. Actitudes y acentos magnificamente calculados logran el propósito de cada momento. Irene López de Heredia supo ser la mujer rebelde, nerviosa, apasionada, que el drama exige (Díez Canedo, 1925).

No es de extrañar entonces que Ernesto Vilches la guardara en repertorio y la representara en su gira por Latinoamérica. De hecho, el actor la escenificó el 14 y 16 de septiembre de 1932, en el teatro Degollado de México.

Pero antes que Vilches, la obra era ya conocida en Argentina, por la puesta en escena hecha por la compañía Matilde Rivera y Enrique de Rosas del 10 al 14 de septiembre de 1926, en el Tívoli, en Barcelona y más tarde, el 29 marzo de 1927, en el teatro San Martín, donde fue recibida con expectación y gran éxito de crítica:

Enrique de Rosas encara su papel con exacto y penetrante sentido del personaje, ofreciendo de él una interpretación inteligente y colorida, que animó con oportunidad o dijo con vigor, según iban exigiendo las alternativas de la pieza, realizando en suma una digna y encomiable labor, que ha quedado como uno de sus trabajos más precisos (Urquiza, 1973: 219).

La obra quedó en repertorio y la volvieron a representar, por ejemplo, en Venezuela, el 29 de septiembre de 1933, en el Teatro Municipal de Caracas.

A partir de 1936, con la guerra civil y la posterior dictadura, varios son los dramaturgos, las compañías y los escenógrafos que se exiliaron en Latinoamérica, donde siguieron sus actividades teatrales. Tal es el caso de la compañía española formada por el matrimonio Benito Cibrián y Pepita Meliá, quienes encontraron su segunda patria en México al acabar la guerra. Esta compañía contaba con la obra Todo un hombre en su repertorio desde 
hacía varios años y con ella habían recorrido España con gran éxito ${ }^{20}$. Por ello, en febrero de 1940, la eescenificaron en el teatro mexicano Arbeu. Un año más tarde, en 1941, la reponen en el teatro Smart ${ }^{21}$ en Argentina ${ }^{22}$ y posteriormente el 19 y 22 de octubre de 1945 en el teatro Degollado de México.

La dirección corrió a cargo de Benito Cibrián y se encargó de la escenografía el español Manuel Fontanals ${ }^{23}$, quien también se había exiliado en México. Lamentablemente, pocos datos se conservan de tal montaje, ya que al ser considerada compañía extranjera no aparece sistemáticamente repertoriada. La crítica alaba el trabajo de los actores que «desempeñaron sus papeles con propiedad y la mayoría brillantemente» (Excelsior, 1940: 10) y de Benito Cibrián, ya que «se adivinaba la constancia de un director preocupado y competente» (Excelsior, 1940: 10).

La puesta en escena fue muy cuidada y «montada con todo lujo de detalles, con elegancia insuperable» (Excelsior, 1940: 10), lo que desde luego contrasta con los preceptos teatrales de desnudez escénica unamunianos. Asimismo, añade que el público aplaudió calurosamente una representación que salía de lo habitual, ya que el crítico confiesa no haber visto «en nuestro país una obra montada con tanta propiedad, ni interpretada con tanta disciplina y sensibilidad artística» (Excelsior, 1940: 10).

Cuatro años más tarde, Magda Haller ${ }^{24}$ puso en escena Todo un hombre en dos ocasiones, el 28 de julio de 1944 y el 12 de febrero de 1945, en el Teatro Principal de la Comedia en Cuba, donde su compañía solía dar sus espectáculos. Ambas representaciones fueron únicas. Este hecho no era inhabitual en la escena cubana, ya que, desde principios de siglo, cuando casi todos los espectáculos eran traídos por compañías profesionales españolas ${ }^{25}$, las fun-

20 Así lo prueban las tesis de doctorado de María Ángel Somalo Fernández, El teatro en Logroño (1901-1950) y de Emilia Ochando Madrigal, La vida escénica en Albacete (1924-1936), defendidas en la UNED, donde se cita la obra Todo un hombre puesta en escena el 25.10.1929 en Logroño y el 2.3.1930 en Albacete. Más representaciones de las obras de Unamuno durante el siglo Xx pueden verse en las tesis de doctorado, dirigidas por José Romera Castillo, ya publicadas y puestas a disposición de los investigadores en http://www.uned.es/centro-investigacion-SELITEN@T. Cf. especialmente la de Alfredo Cerda Muños, sobre la actividad escénica en Guadalajara (México) 1920-1990.

${ }^{21}$ Hasta la década de 1980 se llamó así, para luego pasar a ser Teatro Blanca Podestá hasta 1997, fecha en la que se proyecta el actual Multiteatro, inaugurado en el 2001.

${ }^{22}$ Después de esta puesta en escena, la obra siguió siendo representada en Argentina, pero en pantalla. Se hizo un montaje en Canal 9 en julio de 1972.

23 1895-1972. Formado por Bürmann, fue introducido en el mundo teatral por Martínez Sierra. Se le conoce por sus escenografías de colores agresivos que recuerdan el mundo del postfauvismo.

24 1915-1981. Actriz mexicana que se instaló en Cuba, tras casarse con el actor cubano Otto Sirgo, donde fundó su propia compañía. 
ciones eran diarias y cambiaban el repertorio todos los días, hasta los fines de semana. Además, a mediados de los años 30 , cuando comienzan a surgir movimientos teatrales renovadores, como La Cueva ${ }^{26}$, el Teatro Universitario ${ }^{27}$, el Teatro Popular ${ }^{28} \mathrm{o}$ el Patronato de Teatro ${ }^{29}$, éstos preparaban sus montajes durante todo un mes para subir a escena solamente una vez por la falta de solvencia y al encontrarse con la resistencia de un público acostumbrado a la alta comedia. Este carácter efímero de las representaciones, unido a la falta de interés en la conservación de los documentos relativos a las puestas en escena y a la demolición del teatro Principal de la Comedia (convertido en parque en 1957), hace que no se posean más datos de este montaje según nos ha confirmado el CNIAE ${ }^{30}$.

Precisamente, el Patronato de Teatro, en el marco de la función mensual que daba, escenificó también Todo un hombre, en el teatro Auditórium, el 28 de marzo de 1947. Los actores principales fueron José de San Antón (Alejandro Gómez) y Raquel Revuelta (Julia). El escenógrafo fue Luis Márquez y José Caderecha se ocupó de los efectos luminotécnicos ${ }^{31}$.

Luis Amado Blanco ${ }^{32}$ se hizo cargo de la dirección de la pieza unamuniana y desde un principio dejó claro su concepción del teatro: respetar «todo lo esencial» de la obra, «pero considerándola al mismo tiempo como una especie de partitura, frente a la cual el concertador tiene el derecho y el deber de darnos su versión» (Ichaso, 1947: 8). Un concepto muy moderno del papel del director que provocó el cambio de título de la pieza para devolverla a sus raíces, a la nivola:

25 Durante los primeros años del siglo XX, el teatro cubano era eminentemente español, pues las representaciones corrían a cargo de compañías españolas como Guerrero-Mendoza, Martínez Sierra con la Bárcena, la Membrives con Benavente, Thuillier o la Xirgu y Rivas Cherif, con excepción de los cubanos Luisa Martínez Casado y Alejandro Garrido.

26 Teatro de Arte de La Habana, dirigido por Luis A. Baralt.

27 Dirigido por Ludwig Schajowicz y el español Rubia Barcia, entre otros.

28 Del Partido Socialista, dirigido por Paco Alfonso.

${ }^{29}$ Fundado en 1942 por Ramón Antonio Crucellas, el Patronato de Teatro fue la institución teatral más duradera y dio un impulso al teatro cubano al escenificar obras contemporáneas tanto cubanas como europeas.

${ }^{30}$ Centro Nacional de Investigaciones de las Artes Escénicas.

31 La valía de ambos quedó demostrada en el montaje de La dama del alba de Alejandro Casona, dirigida por Luis Amado Blanco, el cual recibió el premio Talía en 1946 y fue seleccionada como mejor espectáculo teatral por la ARTYC (Agrupación de Redactores Teatrales y Cinematográficos).

32 1903-1975. Amigo de escritores como Federico García Lorca, Alejandro Casona, Juan Ramón Jiménez y otros, colaboró en publicaciones periódicas como Blanco y Negro, Nueva España o Revista de Occidente. Publicó su primer libro de poemas, Norte, en 1928, pero el estallido de la guerra civil le hizo huir a Cuba, donde tenía parte de su familia, en octubre de 1936. 
reivindicó a Unamuno e hizo uso de esa facultad de rebautizo que siempre han tenido los poetas. Sin duda «Nada menos que todo un hombre» es más unamunesco que "Todo un hombre». A un yoísta tan celoso de su integridad [se refiere al protagonista de la obra] no se le debe quitar nada, ni el «nada menos» (Ichaso, 1947: 8).

El tratamiento unamuniano de la obra se mostró también en el trabajo de los actores, los cuales «dijeron y actuaron de acuerdo con la más auténtica de las realidades psicológicas» (Pares, 1947: 19). No es extraño este acercamiento a la pieza, pues Luis Amado Blanco era un gran conocedor y admirador del escritor salmantino como muestra la «pasión e influencia que tuvo sobre él la obra de Unamuno» (González Martell, 2001: 196). La crítica elogió la labor del director, no sólo por sus aciertos en el cambio del título y la construcción de los personajes, sino también porque:

la dirección de «Nada menos que todo un hombre» fue perfecta. [...] El resto de los aciertos escénicos, insuperables. Ritmo, gradación emocional y lenguaje de formas compusieron una magnífica noche teatral [...] Amado Blanco cuidó el montaje con una pulcritud que raya en lo excepcional (Pares, 1947: 19).

En efecto, varios fueron los aciertos de Luis Amado Blanco según la crítica. Primeramente, situó la acción en la época en que Unamuno la escribió, «cuando el ambiente español se conservaba en un rústico olor de provincia, en una martirizada ingenuidad» (Ichaso, 1947: 8), ya que de lo contrario se hubiera quitado sentido a la obra y el conflicto hubiera resultado «materia un tanto anacrónica» (Ichaso, 1947: 8). Además, Luis Amado Blanco realizó supresiones y alteraciones en el texto de Julio Hoyos que contribuyeron a «reducir la escenografía y aligerar la acción» (Ichaso, 1947: 8).

Otros cambios afectaron a la puesta en escena, con la que el director quiso conseguir más efectividad en el drama. Así, por ejemplo, eligió hacer corpórea la presencia del niño, mientras que en la adaptación de Julio Hoyos el hijo nunca aparece y su existencia es tan sólo sugerida:

DON ALBERTO y JULIA que sale por la derecha, descompuesta y nerviosa. D. ALB. ;Julia! ;Julia!

JULIA. ¡Mi hijo! ¡Mi hijo! 'Quiero ver a mi hijo! (Hace sonar una vez el timbre de una pared, y luego dos veces el de otra, asoman por el foro el criado y por la izquierda una doncella) A la doncella: el niño, ique me traigan el 
niño! (Mutis del criado.) A la miss: el niño, ique me traigan el niño enseguida! (Mutis de la doncella.) [...] ¿Pero, y el niño? ¿Y mi hijo? ;Si pudiera sacarle toda la sangre de su padre!... ;Porque es su padre!... ;Y el niño le quiere don Alberto! ¡Le quiere a él, a Alejandro! (Hoyos, 1926: 33-34).

De esta manera, Luis Amado Blanco busca la emoción del público al subrayar el dramatismo de la escena, ya que «en el teatro lo que se ve tiene más eficacia que lo que se oye» (Ichaso, 1947: 8). Unamuno basaba su teatro justamente en lo contrario, por lo que no creemos que este cambio hubiese sido del agrado del escritor que huyó en todo momento de este tipo de efectos y aspiraba a que tales sentimientos fuesen obtenidos por la intensidad de las palabras $^{33}$. Paradójicamente, estos deseos fueron respetados en el final, ya que «reservó todos sus esmeros de director escrupuloso para ese final fúnebre, en que toda truculencia fue limpiamente salvada por un hacer escénico tan digno como eficaz» (Ichaso, 1947: 8). Sin embargo, no todos los juegos escénicos convencieron, ya que en la escena en la que Alejandro enfrenta a Julia y al conde Bordaviella, donde Luis Amado Blanco propone un cambio de tazas, con el que «parece que quiso hacer más patente el aire sarcástico de la escena», el recurso es calificado de «impropio e innecesario» (Ichaso, 1947: 8).

La crítica juzga los efectos de luz cuidados, salvo Pares que lamenta «que en la primera decadencia de luces, el crepúsculo se abatiera con excesiva premura» (Pares, 1947: 19). Tampoco fue del gusto del crítico la decoración que «no estuvo a la altura de la noche teatral», ya que fue desequilibrada entre las diferentes jornadas y «a pesar de reproducir una época de mal gusto aparatoso, dio una réplica demasiado caricaturesca, muy bien realizada, pero con excesivo énfasis en el amazacotamiento de temas» (Pares, 1947: 19), lejos de la desnudez preconizada por Unamuno.

En cuanto a la interpretación, la elección de José de San Antón para interpretar a Alejandro Gómez no convenció, en un principio, a Francisco Ichaso, al no considerarle con la edad adecuada para dar vida a un galán, a pesar de contar con 33 años, por lo que «tuvo que luchar con un obstáculo físico: su figura, su empaque, hasta su propia voz, que tienden más a lo que en la jerga

${ }^{33}$ En efecto, Unamuno decía en el exordio de Fedra «aspiro a que cuanto diga y exprese Fedra, por ejemplo, sea de tal intensidad trágica, que los espectadores - y sobre todo las espectadoras - no tengan que distraerse» (Unamuno, 1959: 392). Además se mostró reacio a manifestar el sufrimiento y la dramaticidad con otro medio que no fuese el de las palabras, ya que «siempre que he visto a algún actor especialista en muertes expirar en escena, me ha parecido aquello más cinematográfico que dramático y casi siempre repulsivo» (Unamuno, 1959: 394). 
escénica se entiende por barba» (Ichaso, 1947: 8). Sin embargo, esta dificultad primera fue superada por el gran profesionalismo de que hizo gala y los años de experiencia al componer un personaje convincente, al que supo dar la tensión contenida y la justa rigidez, sin traicionarlo con exageraciones, destacando por su «natural dominio de sí mismo, aplomo y seguridad» (Ichaso, 1947: 8). Distinto es el caso de Raquel Revuelta, quien obtuvo el Premio Talía ${ }^{34}$ ese mismo año a la mejor actuación femenina. Su «soltura y calidad» (Pares, 1947: 19) fueron ampliamente elogiadas por la crítica que destacó su gran capacidad para emocionar «con su angustiada máscara y su dramática voz» (Ichaso, 1947: 8). Aunque se le achacó cierta «rigidez, cierta dificultad, como si sólo estuviese pendiente del «clímax» próximo» (Ichaso, 1947: 8) en la escenas que requerían menos pasión o sufrimiento.

A pesar de algunas infidelidades al texto y sobre todo a los criterios teatrales de Unamuno, el montaje de Luis Amado Blanco constituyó un buen intento de puesta en escena de una obra de Unamuno. Con los medios de los que dispuso, intentó dar su versión de la pieza y comprendió el carácter intrínseco del drama, aunque, como buen hombre de teatro, quiso revestir la excesiva desnudez unamuniana para acercar la obra del público lo que le valió los aplausos de éste.

Todo un hombre también fue puesta en escena por Francisco Petrone ${ }^{35}$, quien había alcanzado su consagración al participar en la película homónima, realizada en 1943, por Artistas Argentinos Asociados y de la que hablaremos más adelante. Obtuvo tal éxito que durante toda su carrera le acompañó el sobrenombre de todo un hombre. El actor supo igualmente rendir tributo a aquél que le dio la fama, al incorporar la obra a su repertorio y al llevarla durante varios años de gira por toda Latinoamérica.

Primero, la escenificó en Uruguay, país al que se exilió por motivos políticos en 1950. Allí se unió a la Comedia Nacional ${ }^{36}$ con la que dirigió e interpretó la obra de Unamuno en el papel de Alejandro. La escenografía fue realizada por José Echave sobre bocetos originales de Gori Muñoz ${ }^{37}$, otro de

34 Se instituyó en 1946 para reconocer la labor de actores y directores y estimular así la labor teatral.

35 1902-1967. Nombre artístico de Francisco Petraca Mesulla.

${ }^{36}$ La Comedia Nacional de Uruguay se instaura como un intento de teatro independiente, fuera de los dictados empresariales y con una vertiente didáctica de la que se encarga la propia Margarita Xirgu.

37 1906-1978. Estudió en la Escuela de Bellas Artes de San Ferrán en Madrid, donde conoció a García Lorca, a Luis Buñuel y a Ramón Gómez de la Serna. Becado por la Junta de Ampliación de Estudios, estuvo en países europeos como Bélgica o Francia, donde fue discípulo de Copeau. Se iniciará como escenógrafo en el teatro universitario El Búho, pero no será hasta que llegue a Buenos Aires como exiliado republicano, a finales del 1939, cuando se dedique de pleno al teatro. 
los exiliados y que participó también en la película de Artistas Argentinos Asocidos. Después de esta representación en Uruguay ${ }^{38}$, Francisco Petrone la puso de nuevo en escena un año más tarde, el 28 de julio de 1951, en Venezuela. En ella actuaron Mónica Vargas, Enrique Roldán y Jaime Andrade en los papeles principales. A Cuba llegó dos años más tarde, el 30 de enero de 1953, donde la interpretó una vez más en el teatro Martí con su propia Compañía de Comedias y bajo su dirección artística.

Francisco Petrone situó la acción en Madrid, en la época contemporánea, pero su puesta en escena en Cuba no convenció a la crítica y el eco que pudo obtener lo debió sobre todo a su fama como actor y a «su extraordinaria personalidad humana que se impone por encima y por debajo de los fallos o aciertos de su trabajo histriónico» (Amado Blanco, 1953: 3). Luis Amado Blanco dice de la dirección que «a pesar de las ovaciones del público [...] el señor Petrone es un principiante como director, a quien se le escapan [...] lo que es movimiento, ritmo, plástica, etcétera, etcétera, en la cuadratura de un escenario» (Amado Blanco, 1953: 3). Achaca esto a la formación del actor bajo las órdenes de un director y a la falta en esta ocasión de uno verdadero que afine y pula la actuación, ya que «se le ve solo, vacilante, sin aquella perfección que un día logró en el cine» (Amado Blanco, 1953: 3).

El trabajo actoral fue, por lo tanto, de calidad muy variable. Francisco Petrone ofreció una actuación llena de altibajos, que se mejoraba a medida que los actos se sucedían. Esta impresión se debió a un fallo escenográfico, ya que en el primer acto la escena se presentaba «limpia de muebles y acción secundaria» (Amado Blanco, 1953: 3), lo que provocaba una desnudez total donde el actor se sentía perdido por el vacío que le rodeaba «sin poder sujetarse ni apoyarse en nada, [...] sin fuerza, asustado de la largura de sus brazos.» (Amado Blanco, 1953: 3). Esta desnudez podría corresponder a una intención de respetar los cánones impuestos por Unamuno para su teatro, pero no es el caso, ya que durante los siguientes actos, esta situación se corrigió y Francisco Petrone «ya con muebles donde atracar, se fue reponiendo hasta un tercer acto vocalmente sincero que fue directo al blando corazón del respetable» (Amado Blanco, 1953: 3). La actuación del resto de la compañía fue calificada de discreta, a excepción de Jaime Andrada que daba vida al conde Bordaviella y cuyo trabajo de interpretación cayó en la exageración, ya que,

${ }^{38}$ La puesta en escena no debió pasar desapercibida, ya que, por la misma época, a comienzos de los 50, Juver Salcedo realizó una lectura radiofónica en el SODRE con el elenco de la Comedia Nacional. De esta versión radioteatral no ha quedado registro, ya que era en vivo y todavía no se grababa. 
según el crítico, «confundió el escenario con una pista de circo» (Amado Blanco, 1953: 3).

Francisco Petrone parece no haber respetado los deseos teatrales unamunianos, tal vez por desconocimiento o por disensión de pareceres como es el caso de Luis Amado Blanco, quien no entendía el teatro como un espectáculo meramente de palabra.

Ninguna de las puestas en escena se ajusta a las teorías teatrales de Unamuno, si bien es cierto que el texto utilizado no es el que el escritor hubiera querido. En todos los casos, la obra se ajustó más a los gustos del público, proponiendo una escena más revestida de lo que el dramaturgo hubiera deseado $^{39}$. Sin embargo, esta obra ha sido la pieza de más éxito y que ha conocido más representaciones y versiones. Recientemente, Tankred Dorst y Ursula Ehler realizaron una nueva versión de Nada menos que todo un hombre, titulada Fernando Krapp me ha escrito esta carta, en 1992.

A estos éxitos teatrales han de añadirse las diversas y desiguales adaptaciones cinematográficas de la obra. La primera película, que popularizó y contribuyó aún más al éxito de la pieza, fue dirigida en 1943 por Pierre $\mathrm{Chenal}^{40}$. Fue realizada por los Artistas Argentinos Asociados ${ }^{41}$ en los estudios San Miguel y Ulyses Petit de Murat y Homero Manzi se ocuparon del guión y Francisco Petrone y Amelia Bence interpretaron los papeles principales. La música fue compuesta por Lucio Demare y la escenografía fue realizada por Gori Muñoz. Todo un hombre fue la primera película argentina de Pierre Chenal y la tercera que realizaron Artistas Argentinos Asociados, quienes cuidaban la calidad artística como lo prueba el contrato que firmaron con Gori Muñoz al que obligan a respetar «el estricto cumplimiento de la finalidad artística» (Peralta, 2002: 50). Hay que considerar que era una tarea delicada, pues «se trataba de un extranjero que llevaba a la pantalla una obra extranjera: la novela de Miguel de Unamuno, un escritor particular-

\footnotetext{
39 Decía en el exordio de Fedra «no quiere necesitar esta tragedia del concurso de pintor, escenógrafo, ni de sastre y modisto, ni de peluquero» (Unamuno, 1953: 392).

40 1904-1990. Uno de los realizadores más conocidos y sólidos del cine francés que seguía la corriente realista predominante entonces y que llevó a cabo adaptaciones como la de Crimen y castigo de Dostoievski, en 1935, o El difunto Matías de Luigi Pirandello, en 1937, antes de exiliarse en Argentina, en 1942, para huir de los alemanes debido a su origen judío.

41 Productora independiente argentina que intentó hacer películas de calidad que fuesen al mismo tiempo comerciales y rentables. Estuvo integrada, en sus orígenes, por dos grandes figuras del teatro nacional: Elías Alippi y Enrique Muiño, a los que se unieron los jóvenes actores Francisco Petrone y Ángel Magaña, además del consagrado Lucas Demare y el productor Enrique Faustín. Contaron asimismo con la colaboración de los guionistas Ulyses Petit de Murat (1907-1983) y Homero Manzi.
} 
mente difícil de trasladar al cine» (Manzi, 2003: 10), pero el director cumplió plenamente con los objetivos de la productora, ya que «fue un éxito artístico y comercial» (Manzi, 2003: 10).

También Gori Muñoz cuidó mucho la escenografía para que reflejase la personalidad de los protagonistas. Por ejemplo, la diferencia de posiciones económicas se refleja a través de la casa arruinada de la familia Yáñez, que guarda los vestigios de un pasado mejor, frente a la riqueza y ostentación de los que hace gala sin complejos Alejandro Gómez. Se nota también la desigualdad entre las dos alcobas de Julia, la de soltera y la de casada: «en el tocador de soltera había una caja bastante grande que caracterizaba a una persona que tiene mucho que guardar [...] el tocador y el espejo de la casa del Recodo son más grandes y lujosos, aquí los tarritos de cristal se multiplican» (Peralta, 2002: 50). Estas diferencias de casa se hacen notar también en la decoración de los dos salones, el de los Yáñez, acogedor, y el de Alejandro Gómez, en el que «una enorme escalera, las columnas, el amplio espacio y la barroca chimenea crean un ambiente gélido» (Peralta, 2002: 51), que refleja la aparente falta de sentimientos de Alejandro y su deseo de mostrar de manera ostentosa su riqueza. Los contrastes continúan con los despachos, ya que el de Alejandro «denota una gran actividad, con material desplegado sobre las mesas, con mucha luz» (Peralta, 2002: 51), lo que muestra cómo los negocios de Alejandro son lucrativos, frente a la decadencia del de su suegro que «tiene la apariencia de un lugar que lleva bastante tiempo cerrado» (Peralta, 2002: 51).

Ulyses Petit de Murat participó igualmente en el guión de la segunda película, aunque sin Homero Manzi, que se realizó once años después, en 1954, en México. Esta vez la obra se tituló La Entrega y fue realizada por Julián Soler con Filmex y protagonizada por Arturo de Córdova, en el papel de Alejandro Gómez y Marga López, en el de Julia. Ambos guiones no tienen diferencias sustanciales, como explica el propio Ulyses:

Chenal vio a Julia como una obsesa retenida y plena de un conflicto muy hondo y secreto; Soler la ha visto más desbordada, en el raudal de la neurosis; la versión argentina retenía la escena burlesca del desafío a duelo; en la mexicana he resumido el incidente, quitándole su aspecto grotesco y llevándolo a un solo escenario, el del club de provincia; la versión argentina arrancaba con una brusca descripción del estado decadente de los Yánez; la mexicana tiene un prólogo, antes de los títulos, donde se muestra el origen del rencor de Alejandro, arrojado de esa ciudad y, en seguida de los títulos, se muestra al curioso personaje ejerciendo la venganza largamente premeditada al derruir, una a una, las esquinas (Petit de Murat, 1954: 13-14). 
Escribió los dos guiones conociendo la existencia de la adaptación teatral de Julio Hoyos, pero sin tenerla en cuenta, ya que, según él, «carecía de calidad y fuerza poética, ésta última necesaria para salvar la terrible, descarnada acritud de ciertos momentos del relato» (Petit de Murat, 1954: 9).

Sus guiones, aunque conservan parte de los diálogos de la nivola de Unamuno, poseen cambios notables con respecto a ésta, como el hecho de cambiar el final: cuando Julia enferma, Alejandro la lleva a la playa donde le declara su amor, antes de que ella muera de una enfermedad del corazón y él, con el cadáver de su esposa, se interne en el mar. Además, en vez de situar la escena en España, como era el caso de la mayoría de las adaptaciones teatrales, la acción transcurre en Latinoamérica, en el primer caso en Argentina en el Tigre, lugar cercano a Buenos Aires y en el segundo en México, en Guanajuato. También se incluyen escenas nuevas y personajes relacionados con la cultura latinoamericana como la de los isleños a los que ayuda Alejandro Gómez. Pero la infidelidad más grande fue la de cambiar el sentido intrínseco de la obra al modificar la concepción de Alejandro Gómez:

Francisco Petrone, según el consenso general, era un gran actor que debía vivir su vida artística fuera de la órbita que - tan convencionalmente - se designa como propia del galán. Para él las explosiones pasionales de todo orden, la acción, la furiosa pelea, el arrebatado idealismo. ¡Pero nada de meterlo en los laberintos del amor, en un juego definidamente de pareja, como el que proponía «Nada menos que todo un hombre»! (Petit de Murat, 1954: 10).

Aunque la película fue todo un éxito y supuso la consagración de Artistas Argentinos Asociados, por la que obtuvo un premio de los miembros de la ARTYC, no le falta razón a Luis Amado Blanco cuando se mostró algo más crítico con la adaptación, que:

a pesar de sus indudables bondades, de su superior categoría artística, no sólo falseaba el tipo protagónico adaptándolo a las exigencias ambientales de la patria del tango, sino que insistía una vez más en suponer a Alejandro Gómez como un carácter directo, de supermacho, y no como un carácter agónico como lo entendió el profesor de Salamanca (Amado Blanco, 1953: 3).

Sin embargo, en la tercera película, realizada en 1983, la obra unamuniana sólo sirvió como base argumental para el guión. Titulada también Todo un 
hombre, la película fue dirigida por Rafael Villaseñor Kuri ${ }^{42}$ con guión de Rafael García Travesi ${ }^{43}$. Esta película estuvo interpretada por el popular cantante de rancheras, Vicente Fernández. En esta producción se cambiaron los nombres de los protagonistas, su carácter, sus relaciones e incluso el final en el que Joaquín Barrera (el Alejandro Gómez de Unamuno) no se suicida.

En todas las películas, se adecua el argumento de Nada menos que todo un hombre para componer producciones que se ajusten a la cultura y gustos del público ${ }^{44}$. A medida que los años pasan, las versiones se distorsionan y la obra de Unamuno es cada vez menos reconocible.

Si bien Unamuno representó todas sus obras teatrales en España, debió realizar innumerables esfuerzos para que sus piezas fuesen montadas en escena y cuando lo consiguió, tuvo que conformarse, en la mayoría de los casos, con escenas pequeñas o alternativas, como pasó por ejemplo con Fedra, que tan sólo llegó a representarse once años después de su creación en el Círculo de Bellas Artes. En efecto, sus obras encontraban difícilmente teatros interesados en prestar sus escenas y menos aún elencos dispuestos a arriesgarse con ellas, como lo reconoce el propio Rivas Cherif:

\begin{abstract}
Ni Enrique Borrás ni Ricardo Calvo llevan a la América española ningún drama del autor de Fedra, que varios tiene ya acabados o en gestación. No será por lo mucho bueno que a uno y otro les sobre en el repertorio. Salvo con El bandido de la sierra de Ardavín, el popular intérprete de Tierra baja (E. Borrás) no ha podido lograr en su última temporada de Madrid un solo éxito apreciable con las comedias menos que medianas, y aun diríamos peores que malas algunas. [...] El nombre de Unamuno bastaría, en cambio, para compensar el fracaso de sus dramas (Rivas Cherif, 1924).
\end{abstract}

Diferente fue su caso en América Latina durante los primeros años del siglo XX, donde sus obras se representaron en los teatros argentinos, el Ateneo

${ }^{42}$ Conocido por su larga trayectoria en el cine mexicano, pues comenzó como aprendiz a los quince años, debuta como director en 1976 con Mil caminos tiene la mиerte, una película innovadora dentro de los films de acción y en 1978 firma un contrato en exclusividad con Gregorio Wallerstein para dirigir las película de Vicente Fernández, compromiso que adquiere durante casi 18 años.

43 1910-1984. Llegó a ser uno de los escritores mexicanos más prolíficos de los años 1960 y 1970 , cuando trabajó muy de cerca con productores como Roberto Rodríguez y Gregorio Wallerstein.

44 Tal es el éxito de la novela y el anclaje en la cultura latinoamericana que en Perú se hizo una telenovela llamada Todo un hombre, basada en la novela de Unamuno en 1983. Fue producida por la cadena de televisión Panamérica TV Canal 5, bajo la dirección de Luis Llosa Urquidi y con la actuación de Gustavo Mc Lennan. En 1983 es precisamente cuando esta cadena reanuda el funcionamiento de su área dramática, produciendo grandes programas como la telenovela Carmín, muy exitosa en los ochenta. 
y el San Martín, ambos reconocidos por su prestigio. Además, sus piezas fueron puestas en escena por compañías de teatro que buscaban la renovación del teatro latinoamericano, como las de Enrique de Rosas (1926 y 1927) y Luis Arata (1934). De esta manera, su teatro encontraba por fin el lugar deseado por el escritor dentro de los intentos de renovación:

Miguel de Unamuno [...] ha vuelto a encontrar intérpretes argentinos. [...] Los actores españoles, en general, no se muestran muy dispuestos a incluirlas en su repertorio y las compañías que llegan hasta Buenos Aires acaso las ignoran [...] corre suerte parecida a la de otros autores eminentes de su país, la de Ramón del Valle-Inclán, la de Jacinto Grau, desconocidos o desterrados de los escenarios, cuando son precisamente los más significativos valores del moderno teatro español (La Nación, 1934).

Hasta 1944, las representaciones repertoriadas tienen lugar exclusivamente en Argentina y en México. De ellas, tan sólo dos son puestas en escena por compañías españolas: la de Vilches, seguramente motivado por el éxito anterior de Todo un hombre en España, y la de Benito Cibrián y Pepita Meliá. Como ellos, otros exiliados (Manuel Fontanals, Gori Muñoz, Luis Amado Blanco o Pierre Chenal) contribuyeron a la difusión y a la popularización de la obra del escritor salmantino en América Latina. Su labor fue de gran importancia, no sólo para la divulgación del teatro de Unamuno, sino también para la renovación del teatro latinoamericano. Así lo declara Roger González Martell al hablar del desarrollo del teatro cubano que «tuvo mucho que ver con la llegada de intelectuales europeos, principalmente españoles, a fines de la década de los años 30» (González Martell, 2001: 187).

Desde luego, la obra más representada es la adaptación de Nada menos que todo un hombre, que fue la única en ser montada o adaptada al cine desde los años 40 hasta 1954, con excepción de la puesta en escena de El Otro por el Teatro del Pueblo. Pero también es su obra más deformada y la que menos respeta sus preceptos teatrales. A partir de esos años, las únicas representaciones están fundamentalmente motivadas por la fama alcanzada por el escritor, así, por ejemplo, en 1964, con motivo de la conmemoración de su nacimiento.

En los últimos años se observa un resurgimiento del teatro del escritor salmantino en Latinoamérica de la mano de directores como Javier Vidal (1986) o Daniel Ruiz (2001), los cuales han mostrado a lo largo de su carrera su preocupación por ofrecer obras renovadoras y de calidad. Ambos montajes ponen de realce la esencia del teatro unamuniano: la representación de Ruiz se 
atiene a los preceptos de desnudez escénica, incorporándola a un nuevo tipo de puesta en escena que cada año gana adeptos, y la de Vidal, gracias a una buena comprensión de la filosofía del autor, es un montaje inteligente donde los elementos escénicos completan los vacíos dejados por el texto y ponen la palabra de relieve.

Estos montajes prueban que los renovadores siguen considerando el teatro unamuniano como una fuente de inspiración válida. Además, en 1995, parte de la obra de Unamuno El hermano Juan fue incluida en la pieza teatral Don Juan o la impunidad $d^{45}$, en la que también se utilizaron fragmentos de textos clásicos como El burlador de Sevilla de Tirso de Molina, La última noche de Don Juan de Rostand, Don Juan o el convidado de piedra de Molière y Don Juan o el amor a la geometría de Frisch ${ }^{46}$. Lo cual demuestra que el teatro de Unamuno es considerado ineludible en el panorama teatral.

\section{REFERENCIAS BIBLIOGRÁFICAS}

AzNAR Soler, M. (1999). «Escena y literatura dramática del exilio republicano español de 1939». En El exilio teatral republicano, 11-53. Sant Cugat del Vallès: GEXEL.

Amado Blanco, L. (1953). «Todo un hombre». Información, 5 de febrero, 3.

CH. (1931). «Teatro». El Sol, Madrid, 20 de mayo.

C., M. (1934). «Tiene calidad de clásica la obra de don Miguel de Unamuno». Crítica, Buenos Aires, 28 de julio.

DíEZ CANEDo, E. (1925). «Todo un hombre, novela escenificada por D. Julio Hoyos». El Sol, 21 de diciembre.

GonZÁlez, J. A. (2003). Cronología del teatro dramático habanero. 19361960. La Habana: Centro de Investigación y Desarrollo de la Cultura Cubana Juan Marinello.

${ }^{45}$ La obra se estrenó en México por CADAC. La adaptación y dirección corrió a cargo de Héctor Bourges y fue reestrenada el 25 de mayo de 1996, en el Foro de Teatro Clásico, con funciones especiales el 22, 23, 24, 29 de noviembre y 1 de diciembre en la Capilla Gótica del Centro Cultural Helénico.

${ }^{46}$ Esta pieza formó parte de un ciclo que tuvo la intención de difundir el teatro clásico: la programación de aquel año contempló, entre otras obras, Los empeños de un engaño de Juan Ruiz de Alarcón, Las mujeres sabias de Molière, Los Caballeros o los chorizos de Pritaneo de Aristófanes y El deleitoso de Lope de Rueda, además de Don Juan o La impunidad. 
GonZÁlez Martell, R. (2001). «Luis Amado Blanco y el teatro en Cuba». En El exilio literario asturiano de 1939. Sesenta años después, 187-199. Gijón: Departamento de Filología Española de la Universidad de Oviedo.

Hoyos, J. (1926). Todo un hombre. Madrid: Siglo XX.

ICHASO, F. (1947). «Patronato: Nada menos que todo un hombre. Escenario y pantalla». Diario de la Marina, La Habana, 30 de marzo, 6-8.

ITZCOVICH, M. (1997). «El fenómeno del teatro semimontado. La otra forma de presentar una obra». Clarín, 31 de agosto, 1 http://www.clarin.com/dia rio/1997/08/31/c-01001d.htm.

Machado, M. (1925). «El teatro». Libertad, 24 de diciembre, 4.

MANZI, I. (2003). «La presencia francesa en el cine argentino». Revista de cine 2, 1. http://www.imagenesdelcine.com.ar/revista.htm.

PARES, F. (1947). «Nada menos que todo un hombre». Información, La Habana, 30 de marzo, 19.

Peralta Gilabert, R. (2002). La escenografía del exilio de Gori Muñoz. Valencia: Ediciones de la Filmoteca.

Petit de Murat, U. (1954). La Entrega. México: Alameda.

Rague, María José (2006). «Cara a cara entre Blanca Portillo e Israel Elejalde». El Cultural, 15 de junio, 38-39.

RIVAS CHERIF, C. (1924). «Teatros. Unamuno y Valle-Inclán». España, 415, 23 de marzo.

RodrígReZ CODOlÁ, M. (1926). «Tívoli. Inauguración de la temporada». La Vanguardia, 9 de septiembre, 10.

Salado, J. L. (1935). «Unamuno dice a Julio Hoyos, adaptador de Todo un hombre, que le ha empequeñecido su novela». $\mathrm{La} \mathrm{Voz}, 4$ de marzo.

[s:f]. (1934). «El Otro de Miguel de Unamuno por la compañía de Luis Arata». La Prensa, Buenos Aires.

[s:f]. (1934). «En la velada se estrenó El Otro, obra profunda». La Nación, Buenos Aires.

[s:f]. (1940). «Meliá-Cibrián estrenaron anoche otro gran espectáculo». Excelsior, 29 de febrero, 10. 
SzUCHMACHER, R. (2005). «Notas sobre el teatro independiente en la ciudad de Buenos Aires». Edición electrónica: http://szuchmacher.blogspot.com/ 2005/03/notas-sobre-el-teatro-independiente-en.html.

UnAmuno, M. DE (1959). Teatro completo. Madrid: Aguilar.

Urquiza, J. J. (1973). Testimonios de la vida teatral argentina. Buenos Aires: Ediciones Culturales Argentinas.

Vargas Llosa, M. (1993). Como pez en el agua. Barcelona: Seix Barral. 